\title{
Ação coletiva transnacional na cadeia de confecção do vestuário e a questão de gênero
}

\section{Resumo}

O objetivo central deste artigo é discutir os processos de transnacionalização sindical na confecção do vestuário. Tendo como estudo de caso a cadeia de produção do vestuário ligada à holding Inditex, proprietária de uma das marcas mais valiosas da indústria têxtil (Zara), partimos da hipótese de que os(as) trabalhadores(as) deste setor enfrentam um problema de ação coletiva ligado aos limites de suas próprias capacidades de agência. A partir de procedimentos de tipo qualitativo com métodos cruzados - surveys, entrevistas, levantamento bibliográfico e arquivístico - para São Paulo capital e tendo como comparação o desastre do edifício Rana Plaza, em Bangladesh, os resultados da pesquisa indicam que na confecção do vestuário, ao contrário de outros setores, a ação coletiva sindical se dilui em arranjos institucionais a partir de iniciativas multistakeholder que acabam por promover processos decisórios de cúpula, com implementação do tipo top-down, sem a influência e participação dos trabalhadores de base, exatamente aqueles(as) que vivenciam a precarização e a violação dos direitos sociais e trabalhistas na cadeia do vestuário.

Palavras-chave: Gênero. Interseccionalidade. Transnacionalização sindical. Confecção do vestuário. Federações Sindicais Internacionais.

\footnotetext{
* Universidade de São Paulo (USP), Brasil.

** Universidade Estadual de Campinas (UNICAMP), Brasil.
} 


\title{
Transnational collective action and gender in clothing industry
}

\begin{abstract}
This article aims primarily to discuss the processes of transnationalization of trade union action in the clothing sector. A case study was conducted on a clothing production chain linked to the holding company Inditex, which owns one of the most valuable brands in the textile industry (Zara), supposing that workers in this sector face difficulties for engaging in collective action due to their weak capabilities of agency. Making use of qualitative methods with mixed techniques - surveys, interviews, bibliographical and archival research- the study focused on São Paulo city and compared its context with the disaster of Rana Plaza building in Bangladesh. Research findings indicate that, as compared to other sectors, trade union's collective action in the clothing industry becomes diluted in institutional arrangements based on multistakeholder initiatives, which ultimately promote top-down decision-making and implementation processes, without influence or participation of grassroots workers, the ones who experience the precariousness of work conditions and violation of social and labor rights in the clothing production sector.

Keywords: Gender. Intersectionality. Trade union transnationalization. Manufacture of clothing. International Trade Union Federations.
\end{abstract}


Sociologias, Porto Alegre, ano 19, no 45, mai/ago 2017, p. 142-174

\section{Introdução}

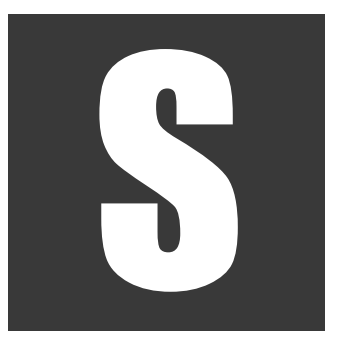

avar $^{1}$, povoado da região metropolitana de Dhaka, Bangladesh, 24 de abril de 2013. Desmoronou o prédio Rana Plaza que abrigava trabalhadores(as) da confecção de roupas para grandes marcas do fast fashion², como Zara/ Inditex, Gap, J.C. Penney, entre outras. O desmoronamento do edifício Rana Plaza ceifou a vida de 1.129 e feriu outros(as) 2.500 trabalhadores(as) que eram, majoritariamente, mulheres, migrantes de áreas rurais, jovens, racializadas, que recebiam por volta de US\$45 mensais (Khan; Witchterich, 2015, p. 1). A tragédia tem sido, frequentemente, comparada a acidentes industriais de larga proporção, como Chernobyl, na Ucrânia (1986), e Bhopal, na Índia (1984) (Bohme, 2014; Matthewman, 2015). No caso em tela, apresenta características similares às do incêndio do Triangle Shirtwaist Factory, em Nova lorque (1911), se guardadas as proporções: em Shirtwaist as chamas mataram 146 trabalhadores(as).

Estado de São Paulo, Brasil, 16 de agosto de 2011. Nesta data, após três outras ocorrências, pequenas oficinas de trabalhadores(as) no setor de confecção do vestuário, também conhecidas como sweatshops ${ }^{3}$, foram flagradas com trabalhadores(as) em condições de trabalho análogo ao de escravo. Neste caso, as oficinas proviam peças exclusivamente para a Zara. As condições incluíam cerceamento da liberdade, retenção de documen-

\footnotetext{
1 Conhecido pela localização do monumento nacional de homenagem aos mortos na guerra de independência de Bangladesh em 1971.

${ }^{2}$ O conceito funciona da seguinte forma, segundo Paulo Corrêa, presidente da C\&A no Brasil: o consumidor "vê um vestido na passarela, [a empresa] põe toda a sua cadeia produtiva para funcionar na tentativa de criar uma peça parecida com aquela e colocá-la à venda no menor espaço de tempo". Dessa forma, o fast fashion induz à moda descartável e à busca do lucro através do prazer efêmero do consumo desenfreado (ISTOÉ Dinheiro, 2016).

3 "Estabelecimento comercial onde os empregados trabalham em condições precárias, sem direitos previstos pela legislação, e onde a remuneração atende ao mínimo necessário para a sobrevivência individual" (www.businessdictionary.com acesso em 13 de março de 2017, tradução nossa); ou "um estabelecimento ou fábrica onde os trabalhadores são empregados por longas jornadas de trabalho, baixos salários e condições insalubres" (Lam, 1992, tradução nossa).
} 
tos por parte dos empregadores, tráfico de pessoas (da Bolívia e do Peru), contratações ilegais, jornadas exaustivas, servidão por dívida e trabalho infantil (Veiga; Galhera, 2015; 2016). De acordo com a pesquisa de campo, trabalhadores(as) bolivianos(as) em sweatshops de São Paulo recebem aproximadamente $\mathrm{R} \$ 705$ mensais para jornadas de 13 horas diárias, ou $\mathrm{R} \$ 1,7$ por peça. Tais trabalhadores(as) são, majoritariamente, homens e mulheres jovens, imigrantes ilegais, racializados(as) em status inferiores ${ }^{4}$.

A indústria de confecção do vestuário é reconhecida mundialmente pelo amplo uso da terceirização, informalidade, baixa remuneração, persistência de acidentes no trabalho, grande mobilidade das empresas por diferentes regiões e/ou países e flexibilidade para a transferência da produção, bem como pela dificuldade dos trabalhadores em se organizarem coletivamente e promoverem agência ${ }^{5}$. Além do problema da ação coletiva ${ }^{6}$, esse é um segmento em que ações de governos e de Organizações Internacionais (Ols) raramente resultaram em medidas efetivas no que se refere à aplicação da lei e à punição das violações trabalhistas, problema conhecido como déficit de enforcement ${ }^{7}$. Mesmo os arranjos institucio-

\footnotetext{
${ }_{4}$ Trabalhadoras e seus filhos sofrem preconceito por carregarem características ameríndias (observação de campo).

${ }^{5}$ Entende-se por agência, aqui, a capacidade de um grupo social de transferir autoridade para um agente, no caso, o sindicato (ou uma representação dos trabalhadores) que possua voz e condições de promover a defesa de seus interesses, de forma autônoma e independente de demais grupos e instituições sociais. No caso do problema de agência aplicado à relação capital-trabalho, ele se refere à dificuldade dos trabalhadores, na condição de principais, em transferirem autoridade a uma entidade representativa como um sindicato, na condição de agente. 6 O problema de ação coletiva se refere àquelas situações em que a busca do interesse individual ameaça o bem-estar coletivo, como acontece quando os trabalhadores entram em greve por melhores salários, mas o resultado coletivo é a falência da empresa (Olson, 1965). A mesma situação é descrita por Östrom (1990), aplicada a um problema ambiental, quando os pastores de ovelha se utilizam de áreas comuns para a criação dos animais. Nesse caso, a busca do interesse individual, ou seja, o aumento das vendas de lã com o maior número de ovelhas coloca em risco a coletividade, porque as áreas comuns não vão suportar um número crescente de ovelhas, o que vai provocar o colapso de todo o sistema de criação e colocar as famílias em situação de vulnerabilidade social.

7 O conceito, em inglês, indica a implementação da lei, daquilo que foi normatizado pelo Direito Público.
} 
nais transnacionais público-privados, constituídos localmente para coibir as violações aos direitos trabalhistas, historicamente, trouxeram pouco alívio aos trabalhadores pobres de países do Sul Global (Veiga; Galhera, 2015).

Diante desse cenário, a expressão marxiana "trabalhadores do mundo, uni-vos!" pode parecer um velho chamado da aristocracia operária rumo a uma internacionalização que pressupõe a classe trabalhadora como um todo homogêneo, sem subdivisões e hierarquias internas, capaz de auto associação voluntária e empoderadora. Um apelo à solidariedade global faria mais sentido para trabalhadores(as) da confecção do vestuário - marcados(as) socialmente, de forma subalterna, por questões de gênero, raça, idade, nacionalidade e divisão do mundo entre Norte e Sul Global - com uma chamada do tipo "trabalhadores(as) do mundo, uni-vos e juntai-vos a ONGs, ativistas, associações de consumidores éticos, autoridades de fiscalização e monitoramento estatal, organizações internacionais e intergovernamentais, empresas com boas práticas de Responsabilidade Social, Federações Sindicais Internacionais e outros movimentos sociais $^{\prime \prime}$. Argumentamos que outros atores políticos são aliados também em arenas transnacionais, e esse é o objeto de estudo no presente artigo. Como resultado do não empoderamento de trabalhadores(as), os processos de transnacionalização sindical do setor são arranjos institucionais de cúpula, baseados em processos decisórios mais fechados, de cima para baixo (top-down). Cabe ressaltar que essas formas de transnacionalização não contam com a ampla participação de trabalhadores(as) de fábricas, pequenas oficinas de costura, ou mesmo de sindicatos de alcance local/ regional e são resultado desse não engajamento. Cabe ressaltar, ainda,

\footnotetext{
${ }^{8}$ Essa constatação não é nova. Para Anner e Evans (2004, p.35), "Em alguns casos, nos quais produtos são feitos em países com baixos salários e vendidos em países de altos salários, as alianças entre 'trabalhadores do mundo' estão sendo substituídas por 'trabalhadores e consumidores do mundo'" (tradução livre).
} 
que o não acesso de trabalhadores(as) a essas instâncias decisórias é derivado das assimetrias de poder calcadas em desigualdade de gênero.

A variável "gênero", por permear a indústria de confecção do vestuário ${ }^{9}$, é importante no desenho do tipo de mão-de-obra que antecede arranjos sindicais internacionais e institucionalizados. Contudo, desde já, é importante reforçar que, dentro da categoria classe trabalhadora, existem subcategorias que definem a institucionalidade setorial e, por consequência, os arranjos institucionais sindicais internacionais. Sabe-se da desigualdade de gênero no mercado de trabalho ${ }^{10}$ e das diferenças setoriais ${ }^{11}$. O que argumentamos é que o gênero importa no mercado de trabalho, principalmente se conjugado com outras variáveis dentro da categoria de classe trabalhadora. As mulheres trabalhadoras mais precarizadas provavelmente serão não brancas, informais, sin papeles, jovens, de zonas rurais, com baixa escolaridade, e do Sul Global. Essas mulheres pouco participam de instâncias de decisão e poder sobre seus próprios futuros, sejam empresas, governos, estados, ou até mesmo sindicatos e associações profissionais. Em outras palavras, o trabalho da mulher, em especial da trabalhadora pobre, jovem, imigrante e racializada do Sul Global, é uma importante variável que influencia indiretamente o desenho da ação sindical transnacional: "Gênero faz o mundo girar" (Enloe, 2014, p. 13) e impacta, inclusive, a própria economia política internacional.

Diante desse quadro, pergunta-se: por que é tão difícil a organização coletiva de trabalhadores(as) na cadeia do setor de confecção do vestuário? Com tantos casos e evidências de violações aos direitos fundamentais do trabalho, por que tem baixa efetividade o enforcement de governos e

\footnotetext{
9 É importante apontar que no setor, por exemplo, na América Central, "em média, 80\% da força de trabalho é feminina e alguns dos abusos mais comuns incluíram assédio sexual, demissão de trabalhadoras grávidas e recusa ao direito de licença-maternidade" (Anner; Evans, 2004, p. 37, tradução nossa).

10 Ver, por exemplo, Hirata; Kergoat, 2007; Hirata, 2010; Guimarães, 2016.

11 Ver, por exemplo, Anner et al., 2014.
} 
Organizações Internacionais? Por que, nesse setor, quando a cooperação acontece, a transnacionalização da militância sindical é acompanhada, na melhor das hipóteses, de outros atores não sindicais em arranjos institucionais de cúpula, com déficit democrático no que se refere à participação de trabalhadores(as) de base? Por que os sindicatos e/ou os representantes dos trabalhadores não saem à frente do processo político para os defenderem, como acontece em vários outros setores industriais?

Argumentamos que a forma de organização da cadeia do vestuário, por ser altamente precarizada, oferece incentivos para a violação de direitos sociais e trabalhistas por conta da alta mobilidade e da pressão permanente por redução de custos (Dicken, 2007). Ademais, particularmente no caso do vestuário, a variável gênero desempenha um papel importante para explicar a dificuldade da ação coletiva sindical no setor. Conjugada a outros marcadores sociais de diferença, como raça, idade e nacionalidade ${ }^{12}$, o gênero articula, de forma flexível, dois mundos outrora estanques: aquele da "fábrica" - controle, tempo, produção, e produtividade, com a dimensão privada de trabalhadores(as) - e o "lar", ou seja, os cuidados com os familiares, o descanso, a alimentação e o "lazer". Essa "sobreposição flexível" entre o "lar" e a "fábrica" é a condição de trabaIho das imigrantes trabalhadoras em sweatshops na cidade de São Paulo (Veiga; Galhera, 2016).

Denomina-se interseccionalidade essa conjunção de marcadores, conceito conhecido nos estudos de gênero (Brah, 2006; McClintock, 1995; Crenshaw, 1991). A inclusão, aqui, da variável gênero justifica-se por sua relativa ausência nos debates que envolvem setores industriais predominantemente femininos, como a confecção do vestuário. Para nós, portanto, as variáveis interseccionais mencionadas são o ponto de partida para a análise: a produção de roupas baseia-se no trabalho mal pago e,

${ }^{12}$ Separados em categorias distintas, neste artigo, apenas por questões analíticas. 
frequentemente, empregado sob condições insalubres e degradantes de mulheres jovens e racializadas do Sul Global. Precarização e condição de gênero são, portanto, duas razões que concorrem para explicar a dificuldade de ação sindical no setor. É importante apontar que também existem limitações atinentes às estratégias sindicais para enfrentar esta situação.

O objetivo desse artigo é analisar as possibilidades e limites da ação coletiva de trabalhadores(as) do setor de confecção do vestuário a partir de um recorte interseccional e de gênero ${ }^{13}$. Destaca-se o caso da empresa Zara, um ícone das mudanças pelas quais passa o setor do vestuário em escala global. A hipótese aqui desenhada é a de que o gênero ajuda a explicar a dificuldade de trabalhadores(as) em promoverem ação coletiva e elegerem representantes que vocalizem seus interesses de forma independente. Para tanto, além da apresentação da pesquisa na qual coletamos os dados que serão aqui apresentados, daremos destaque para o debate em torno da questão de gênero na cadeia produtiva da confecção e vestuário e de como tal questão impacta a ação coletiva dos trabalhadores.

\footnotetext{
${ }^{13}$ Entende-se por "gênero", "elemento constitutivo de relações sociais baseadas em diferenças percebidas entre os sexos" e "uma forma primária de significar relações de poder" (Scott, 1986, p. 1067, tradução nossa). A categoria gênero tem quatro elementos constitutivos: representações simbólicas binárias (por exemplo, Adão e Eva); conceitos normativos dos significados dos símbolos expressados na religião, educação, ciência, leis e doutrinas políticas; uma noção de política e de instituições sociais; e identidades subjetivas (idem). Nota-se que a definição clássica não se contrapõe às teorias contemporâneas, por exemplo, gênero enquanto performance, inclusive não-binária (Butler, 2011). Neste artigo, aproximamo-nos, principalmente, de teóricas interseccionais. Grosso modo, para essas teóricas, não existe uma única categoria mulher, mas mulheres carregadas de "marcadores sociais de diferença" sob situações sociais contingentes (Brah, 2006), que sofrem violências "frequentemente desenhadas por outras dimensões de suas identidades, como raça e classe" (Crenshaw, 1993, p. 1242, tradução livre).
} 


\section{Metodologia, recursos e campo}

O delineamento da pesquisa amparou-se em diferentes procedimentos de tipo qualitativo. Parte dos dados empíricos aqui apresentados foi obtida por meio de pesquisa de campo realizada entre 2013 e 2014, quando foram entrevistadas 72 trabalhadoras bolivianas da cadeia do vestuário na cidade de São Paulo. O procedimento de pesquisa envolveu métodos cruzados, com a utilização de entrevistas abertas semiestruturadas para diferentes stakeholders ${ }^{14}$, a promoção de grupos focais ${ }^{15}$, e a pesquisa observacional, além de levantamento bibliográfico e arquivístico. Ademais, foram coletadas informações a partir de observação participante no movimento de mulheres imigrantes em São Paulo, entre 2012 e 2017, da Marcha Mundial das Mulheres, entre 2013 e 2016, e do movimento estudantil em defesa de direitos de trabalhadores(as) do setor analisado United Students Against Sweatshops (USAS), na Pensilvânia (Estados Unidos), entre 2015 e 2016. Justifica-se a participação nos eventos citados pelo acesso a informações de outros atores sociais (que não trabalhadores/as) nas demandas por justiça social nas cadeias de confecção do vestuário, em especial após o acidente de Bangladesh ${ }^{16}$.

\footnotetext{
14 Em linguagem da área de administração, as 'partes interessadas' (ou stakeholders) são os atores que fazem parte, direta ou indiretamente, do empreendimento, possuem um 'stake', ou seja, fazem uma aposta na viabilidade do negócio (Barbieri; Cajazeira, 2013).

15 'Grupos focais' são uma ferramenta da metodologia qualitativa, em que representantes do grupo social em tela discutem questões controversas coletivamente e, dessa forma, cristalizam posições e visões de mundo que serão posteriormente utilizadas para testar hipóteses e validar procedimentos metodológicos. A técnica do grupo focal foi conduzida pelos pesquisadores em diferentes reuniões com trabalhadoras bolivianas na sede do Centro de Apoio ao Migrante (CAMI) em São Paulo, entre setembro e dezembro de 2013.

${ }^{16}$ A escolha do setor de vestuário justifica-se pela extensão dos problemas sociais e trabalhistas intrínsecos à organização da cadeia, historicamente, tendo em Shirtwaist Factory talvez um dos primeiros registros emblemáticos. A Inditex, holding que controla a Zara, é importante pelo seu tamanho: é uma das maiores empresas globais de vestuário e a que levou às últimas consequências a estratégia corporativa do fast fashion.
} 
Em primeiro lugar, a análise parte da premissa de que a organização da cadeia do vestuário em escala global é a variável explicativa. São as forças que lideram a cadeia (empresas multinacionais e seus fornecedores) que definem a alocação dos fatores (Dicken, 2007). Como se trata de um segmento intensivo em trabalho, os alvos das empresas são os países pobres do Sul Global que dispõem de oferta de mão de obra barata. Trata-se, também, de uma cadeia produtiva dirigida pelas grandes marcas, do tipo buyer-driven (Gereffi, 1994), bastante internacionalizada em Bangladesh (export-led), e voltada principalmente para consumo nacional/ local no Brasil, com emprego de mão-de-obra nacional, frequentemente imigrante (Quadro 1).

Quadro 1. Desenho de Pesquisa

\begin{tabular}{|c|c|c|c|}
\hline \multicolumn{4}{|c|}{ AÇÃO SINDICAL NA CADEIA PRODUTIVA DO VESTUÁRIO } \\
\hline \multicolumn{2}{|c|}{ Organização da cadeia produtiva do vestuário e seus incentivos } & $\begin{array}{c}\text { Variável } \\
\text { Independente }\end{array}$ \\
\hline $\begin{array}{c}\text { Gênero / } \\
\text { interseccionali- } \\
\text { dade }\end{array}$ & $\begin{array}{c}\text { Arranjos institucionais } \\
\text { transnacionais }\end{array}$ & $\begin{array}{c}\text { Ação coletiva } \\
\text { sindical }\end{array}$ & $\begin{array}{c}\text { Variáveis } \\
\text { Dependentes }\end{array}$ \\
\hline & $\begin{array}{c}\text { sweatshops em } \\
\text { São Paulo }\end{array}$ & $\begin{array}{c}\text { caso } \\
\text { Rana Plaza }\end{array}$ & $\begin{array}{c}\text { Objetos } \\
\text { de estudo }\end{array}$ \\
\hline
\end{tabular}

O eixo da análise desagrega a variável dependente em três dimensões: a ação coletiva sindical, os incentivos institucionais, e como a questão de gênero articula transversalmente as duas primeiras no tipo de resposta sindical, a partir de dois estudos de caso: os flagrantes de trabalho análogo à escravidão em sweatshops, em São Paulo (o estudo de caso) e a tragédia de Rana Plaza, em Bangladesh (o caso comparado). A ação 
sindical está vinculada aos incentivos institucionais ${ }^{17}$, na forma de arranjos locais/nacionais ou transnacionais, para os dois casos, e também faz justaposição com a ocorrência de (i)migração de trabalhadores(as).

\section{Organização dos trabalhadores do setor de vestuário: limites e desafios}

A questão das respostas sindicais às violações dos chamados core labor standards ${ }^{18}$ na cadeia do vestuário pode ser considerada de diferentes ângulos. No caso das Ols, é a Organização Internacional do Trabalho (OIT) a autoridade internacional do tipo "ponto focal" ${ }^{19}$ que promove a negociação em torno de padrões trabalhistas e sociais, através de uma arena decisória do tipo intergovernamental. Ocorre que a OIT não possui os instrumentos de sanção contra aqueles governos que ratificam esses padrões, mas não os implementam, ou apresentam baixa efetividade no desempenho dos core labor standards. Os governos nacionais dispõem da prerrogativa de sancionar a não aderência aos padrões trabalhistas previstos em lei, mas o enforcement legal varia conforme o país e a região.

Da perspectiva do setor privado, as cadeias globais de valor organizam-se "sobre" os Estados e Ols (Dicken, 2007), e criam os seus próprios incentivos para se aproveitarem das vantagens de operarem em países onde as vítimas costumeiramente são os(as) trabalhadores(as) po-

\footnotetext{
${ }^{17}$ A abordagem institucionalista em Ciência Política parte da ideia de que as instituições são provedoras de regras e normas que constrangem e, ao mesmo tempo, incentivam o comportamento dos agentes, e que esses as reconhecem para a promoção da ação coletiva (North, 1990; Östrom, 1990).

18 Os chamados Core Labor Standards foram definidos pela OIT em sua Conferência de 1998 em Genebra, e podem ser traduzidos por Direitos Fundamentais do Trabalho, ou seja, são reconhecidos como aqueles direitos do trabalho considerados basilares por governos, Ols, e pela sociedade civil global.

19 Uma autoridade "Ponto focal" é aquela cuja fonte regulatória é única e cujo ambiente institucional não apresenta competidores, como são os casos da OIT, para padrões trabalhistas, e a OMC, para o comércio internacional (Büthe; Mattli, 2011).
} 
bres do Sul Global, frequentemente imigrantes e mulheres, sob a cumplicidade de governos determinados a atrair investimentos na forma de atividades geradoras de emprego e renda a qualquer custo: o chamado nivelamento por baixo (race to the bottom). Dessa forma, essas são duas condições necessárias (mas não suficientes) para explicar a fragilidade da ação coletiva sindical.

A literatura específica sobre o problema de agência no caso da relação entre trabalhador (principal) e sindicato (agente), e que trata das redes sindicais internacionais (como agentes do principal) como a variável a ser explicada (VD), divide-se em sete diferentes abordagens: (a) a que explora as próprias estruturas internas e externas das redes sindicais internacionais; (b) a que estabelece relações entre o nível de militância de sindicatos, o Estado e as cadeias produtivas lideradas pelas empresas; (c) os recortes que discutem as campanhas corporativas estratégicas contra as multinacionais; (d) aquelas que privilegiam perspectivas normativas do tipo alterglobalização (outra globalização); (e) aquela que destaca a importância da capacitação e formação educacional; e (f) aquela que analisa o papel da liderança sindical e seu capital político no engajamento do sindicalismo.

Na primeira abordagem, Gray (2015) entende que as redes transnacionais podem apresentar coesão (alta ou baixa), e reconhecimento externo ${ }^{20}$ sobre suas atividades. Destaca-se, também, o reconhecimento de incentivos externos à rede, como as iniciativas de diálogo social, os Acordos Marco-Internacionais e outros mecanismos reguladores, como os

\footnotetext{
${ }^{20}$ Coesão interna, de acordo com Gray (2015), é expandida através de reuniões regulares, estrutura organizacional institucionalizada, troca de informações, pesquisa corporativa, comunicação regular, trocas entre trabalhadores(as), e campanhas de solidariedade. Reconhecimento externo inclui diálogo social internacional, Acordos Marco-Internacionais, outros acordos internacionais, e Códigos de Conduta. Estratégias sindicais internacionais têm, para Gray (2015), cinco dimensões: pesquisa, campanhas, ações integradas, cogerenciamento de regulação internacional, e apoio em comunidades. Essas variáveis resultam em redes das Federações Sindicais Internacionais, redes consultivas, redes com partes sindicais, e redes consolidadas.
} 
chamados Códigos de Conduta corporativos. Essa perspectiva de análise, contudo, não explica os motivos que levam as redes, com todas essas características, a não traduzirem esforços coletivos em bem-estar aos(às) seus(suas) trabalhadores(as) diretos(as) e indiretos(as).

Uma resposta à dificuldade da ação coletiva sindical encontra-se em âmbito doméstico. Como explica Anner (2011), no modelo latino-americano (neo)corporativista, as respostas sindicais não levam, necessariamente, ao internacionalismo. Nível de militância, ideologia, relação capital-trabalho, papel do Estado e da justiça e perfil de cadeia produtiva são as variáveis que levariam a quatro arranjos institucionais diferentes: clientelismo, pactos diretos entre trabalhadores(as) e empresas, campanhas internacionais com ONGs, e redes sindicais internacionais. Embora o modelo seja robusto, não explica a constituição de instituições a partir do gender imbalance (em sindicatos, estados, empresas etc.).

As Campanhas Corporativas Estratégicas contra multinacionais (Juravich; Bronfenbrenner, 1999) não abordam as causas estruturais da precarização de cadeias produtivas com base em perspectivas interseccionais - privilegiadas neste artigo -, apesar de reconhecerem que "o movimento sindical mundial é dividido dentro e entre países, setores, indústrias, regiões e hemisférios" (Bronfenbrenner, 2007, p. 222, tradução nossa).

Já no caso da abordagem normativa de alterglobalização, as propostas seriam de social unionism através, por exemplo, de "coalizões entre os interesses trabalhistas, ambientais e de justiça social, bem como alianças com ONGs, movimentos de mulheres, organizações de consumidores e comunidades" (Webster; Lambert; Bezuidenhout, 2008, p.193, tradução nossa. Ver também Sousa Santos, 2007; Waterman, 1993; Anner, 2006). Essas perspectivas não problematizam a questão de gênero como variável relevante.

No que se refere à quinta abordagem, não há dúvidas de que a capacitação e a formação educacional no movimento sindical internacional, 
especificamente nas Federações Sindicais Internacionais, acaba sendo importante (Croucher; Cotton, 2009). Entretanto, é igualmente importante pensar se essa educação reduz as assimetrias de gênero ou se as reforça.

Por fim, a perspectiva da ação sindical internacional, que trata dos líderes sindicais e de seus capitais culturais (Rombaldi, 2012) está relacionada às experiências masculinas nos setores metalúrgico e de telecomunicações. Essa perspectiva, talvez uma das mais importantes quando tratamos da hierarquização existente nas instituições sindicais internacionais, pode passar a ter referências de gênero em debates futuros.

Das pesquisas até o momento realizadas sobre internacionalização sindical no segmento de confecções, são poucas as que consideram o gênero como uma variável relevante para o desenho da investigação científica (Louie, 2001; Ho et al., 1996; Lynch, 2007; Collins, 2003). Partimos do conceito de interseccionalidade para contribuir com essa agenda de pesquisa. O conceito traduz o fato de que o gênero é conjugado com outras variáveis, ou marcadores sociais de diferença, para a construção de uma sujeita social inserida de forma subalterna em sociabilidades diversas. Dessa forma, se fosse possível desenhar uma pirâmide social internacional no mercado de trabalho, trabalhadoras jovens, marcadas racialmente como não-brancas ${ }^{21}$ e imigrantes ou migrantes rurais do Sul Global, teriam mais chances de ocupar os postos mais precarizados. Em consequência, suas possibilidades de associação com vistas à ação coletiva e à agência são prejudicadas, em razão dessa precarização. Assim, as formas de internacionalização sindical dos setores nos quais tais trabalhadoras estão usualmente inseridas não contam com sua presença de base, isto é, com a participação direta de trabalhadoras nos sindicatos, o que acaba por favorecer a participação de outros atores políticos em arranjos institucionais de cúpula.

${ }^{21}$ Como negras, ameríndias, pardas, indígenas e etc. 
Mas como está socialmente desenhado o trabalho da mulher na cadeia produtiva da confecção do vestuário?

3. Cadeias produtivas do vestuário e a variável gênero

As questões estruturais da confecção do vestuário são bem explicadas pelo modelo de Gereffí22 (1994), ainda atual. Estão ligadas à estrutura de input-output na confecção de bens (aumento de valor agregado ao produto), territorialidade (produção e distribuição) e estrutura de governança (autoridade e relações de poder que determinam como recursos financeiros, materiais e humanos são alocados). Nesse modelo, denominado pelo autor de buyer-driven, os locais de produção estão descentralizados em países exportadores do Sul Global ${ }^{23}$.

No modelo de Gereffi (1994) falta, contudo, considerar a variável gênero conjugada a outros marcadores sociais de diferença, como raça ou etnia. Nos dois casos apresentados, as trabalhadoras compartilham algumas características interseccionais: são jovens, imigrantes, de áreas rurais, do Sul Global, portadoras de marcadores raciais que as inserem de forma subalterna nesse mercado de trabalho ${ }^{24}$. No caso de São Paulo, a pesquisa com trabalhadoras bolivianas do vestuário constatou que a diáspora da Bolívia ${ }^{25}$ para a cidade faz parte de estratégias de emancipação, individuais ou familiares (Veiga; Galhera, 2015; 2016).

A respeito da pergunta feita em entrevista individual "Por que você escolheu o Brasil?", as mulheres bolivianas indicaram razões como "laços anteriores [de parentesco ou amizade]" (60\%), "aspectos econômicos"

\footnotetext{
22 Gereffi (1994) diferenciou dois tipos de cadeia produtiva: producer-driven, dirigida pelo início da cadeia (setores de mineração, petróleo e gás), e buyer-driven, liderada pelo fim da cadeia, ou seja, pelo consumidor final.

${ }^{23}$ O autor utiliza o termo "Third World countries" (Gereffi, 1994).

${ }^{24} \mathrm{Em}$ mensuração qualitativa, a partir de trabalho de campo com trabalhadoras bolivianas em São Paulo, notamos que aquelas provenientes de áreas rurais, de pele mais escura, ocupavam os postos de trabalho de menores remuneração e status social nas oficinas de costura.

${ }_{25}$ As mulheres são provenientes de La Paz (67\%), Cochabamba (18\%), Oruro (8\%), Sucre (4\%) e Potosí (3\%).
} 
(17\%) e "recomendação de terceiros(as)" (6\%). A maioria das entrevistadas (90\%) morava no mesmo local em que trabalhava. O fato de o lar e o trabalho ocuparem o mesmo espaço físico trouxe resultados surpreendentemente significativos: conforme mencionado, as trabalhadoras conseguem articular alta flexibilidade e produtividade ao combinarem trabaIho reprodutivo (cuidado com filhos/as, roupas, limpeza da casa, comida) com a produção da costura. O "atrativo" desse tipo de trabalho está na renda obtida e na possibilidade de conjugar a costura com as obrigações domésticas, a despeito da jornada exaustiva. Mulheres oriundas de áreas rurais, geralmente de pele mais escura, ocupam os postos de trabalho com menores remuneração e status (limpeza, ajudante-geral, overlock ${ }^{26}$ ). Mulheres casadas ou em união estável, geralmente mais velhas, ocupam postos mais bem remunerados e de maior status social (como o de retis$\operatorname{ta}^{27}$ ). A contribuição dos homens para o trabalho reprodutivo é marginal ou nula ${ }^{28}$. Isso indica que o gênero é, de fato, um elo importante entre o mundo privado do trabalho reprodutivo e o cálculo "fabril" da produção das peças para atender às encomendas.

Sendo assim, a inclusão da variável gênero à discussão e ao estudo de caso da cadeia produtiva de confecção do vestuário em São Paulo traz um novo elemento para o modelo de Gereffi (1994). Trata-se de uma cadeia produtiva de alta mobilidade e precarizada, que opera sob um ambiente institucional de regulação pública com coerção do Estado efetiva e, por essa razão, reveladora do escopo e profundidade das violações

\footnotetext{
${ }^{26}$ Overloquista é a profissional que realiza, principalmente, a função de cozer além de outras funções gerais e menores dentro da confecção, como reparação, corte, pregagem.

27 Retista é a profissional que opera a máquina reta. De acordo com nossas interlocutoras, são profissionais mais qualificadas, que têm a capacidade de realizar funções mais desafiadoras, como a costura sem desvios.

28 De acordo com dados obtidos no campo, a ajuda masculina acontece de forma diminuta, em funções "limpas", como lavagem de roupas, em primeiro lugar. Em segundo lugar, figura o cuidado com crianças, seguido de funções na cozinha e, por último, apenas três das 72 entrevistadas mencionaram ajuda masculina na limpeza.
} 
trabalhistas, ao menos no caso da região metropolitana de São Paulo ${ }^{29}$. Essa cadeia se torna mais "atrativa" às mulheres trabalhadoras ao vincularem o "lar" à "fábrica". Essa divisão de trabalho conduz à relação de poder assimétrica entre gêneros, que acaba sendo reproduzida em toda a cadeia (Veiga; Galhera, 2015; 2016).

\section{Ação coletiva: possível transnacionalização sindical?}

A tragédia do edifício Rana Plaza e o caso dos sweatshops em São Paulo guardam um traço em comum: paradoxalmente, trabalhadores(as) envolvidos(as) não participam, em nenhum momento, do processo de tomada de decisões para a melhoria da governança e da regulação, do monitoramento de padrões de saúde e segurança e, mesmo, de denúncias de trabalho análogo à escravidão, no que diz respeito às empresas e autoridades envolvidas na constituição dos hubs locais da cadeia do vestuário.

Nesse contexto, o setor da confecção não tem experimentado o mesmo protagonismo sindical de redes internacionais bem estabelecidas como BASF, Mercedes-Benz e Gerdau. No mesmo sentido, em termos de sindicalismo internacional, observa-se que os desenhos institucionais e repertoires of contention (Tilly, 1986) ${ }^{30}$ são formulados de forma top-down, sem poder delegado a uma autoridade constituída (sindicatos) de forma genuinamente autônoma e resultante da experiência de interação coletiva dos(as) trabalhadores(ras) de base, em uma dinâmica participativa bottom-up.

Em redes internacionais mais bem-estruturadas, as possibilidades de agência, ou seja, de transferir o poder delegado à representação sindical,

\footnotetext{
${ }^{29}$ Há registros de violações trabalhistas no interior de São Paulo e em outros centros de produção de confecções como o Estado do Ceará, em Buenos Aires (Argentina) e em Los Angeles (Estados Unidos), dentre outros.

30 Segundo a definição de Charles Tilly, é o "conjunto de meios que um grupo tem para fazer reivindicações distintas em diferentes indivíduos ou grupos" (1986: 4, tradução nossa).
} 
o estabelecimento de repertórios de luta e a própria cooperação internacional têm se desenvolvido por meio da constituição de agendas coletivas. Tais agendas são negociadas em encontros periódicos, ou através da constituição de intranet e de outros facilitadores de comunicação como mailing lists, de incentivos a arranjos institucionais do tipo "Comissões de Fábrica", jornais, ações de solidariedade internacional, paradas sincronizadas em mais de uma fábrica e lobbies, isto é, ao fim e ao cabo, tudo aquilo que contribui para o fortalecimento da própria instituição sindical ${ }^{31}$.

E no setor analisado?

Beverly J. Silver (2008), inspirada em Erik Olin Wright (2000), traz uma diferenciação entre poder associativo e poder estrutural que acreditamos ser um bom ponto de partida para a diferenciação das fontes de barganha entre os diversos grupos de trabalhadores(as) da economia globalizada. Poder associativo "consiste nas 'várias formas de poder que resultam da formação de organização coletiva de trabalhadores' - dos mais importantes, sindicatos e partidos políticos" -, enquanto que o poder estrutural "consiste no poder que emerge de trabalhadores(as), 'simplesmente de sua localização (...) no sistema econômico'” (Wright, 2000, p. 962 apud Silver, 2008, p. 13).

Expandimos o conceito de poder associativo para abordamos, a seguir, organizações, grupos, coletivos e movimentos sociais, dentre outros, bem como seu modus operandi, a partir dos casos Rana Plaza e de sweatshops em São Paulo. É importante abordar o caso do edifício Rana Plaza, mesmo não sendo propriamente um estudo de caso, por dois motivos específicos. Em primeiro lugar, o desastre abriu novas formas de governança internacional da holding Inditex em escala global, afetando, inclusive, o nosso estudo de caso (sweatshops em São Paulo). Em segundo

31 Ver, por exemplo, Gray, 2009 e 2015. 
lugar, o incidente guarda diversos paralelos com as sweatshops de São Paulo, em especial, o problema de agência derivado de desigualdades de gênero, raça, idade e condição e migrante, já que a maior parte da mão-de-obra era constituída por trabalhadoras jovens e racializadas de áreas urbanas do Sul Global, e o desenho institucional da ação sindical tinha perfil de cúpula, com processo decisório top-down.

O desabamento do edifício Rana Plaza produziu reações por parte de diversas organizações, especialmente de grupos sindicais e rights-based, como: OIT, IndustriALL e UNI Global Union, United Federation of Garments Workers, National Garment Workers Federation, Clean Clothes Campaign e Workers Rights Consortium ${ }^{32}$. O desastre produziu, ainda, novos incentivos para a cooperação entre diferentes atores, e trouxe a negociação de novas regras em processos decisórios mais participativos que, por sua vez, resultaram tanto em novos arranjos institucionais quanto na ampliação de direitos sociais e trabalhistas, agora constituídos e reconhecidos em arenas propriamente transnacionais.

Em primeiro lugar, após o desastre do edifício Rana Plaza, a OIT reagiu de diferentes formas, oferecendo corpo técnico e ajuda humanitária recusada pelas autoridades do país (The Economist, 2013) -, publicização ampla, e o encaminhamento de soluções de curto e médio prazo. Logo durante o primeiro mês após o desastre, a OIT enviou a Bangladesh uma alta missão tripartite com outros stakeholders. Uma coalizão doméstica de partidos e movimentos sociais submeteu ao Parlamento bengali uma sugestão de reforma trabalhista. Uma comissão especial visitou a fábrica e outros locais de trabalho inseguros, iniciou o recrutamento de inspetores,

\footnotetext{
32 IndustriALL e UNI Global Union são organizações sindicais internacionais do ramo. United Federation of Garments Workers e National Garment Workers Federation são as associações de classe envolvidas nos arranjos institucionais derivados do caso Rana Plaza, alinhando-se com Ols. Clean Clothes Campaign é uma organização dedicada à melhoria de condições de vida e trabalho especificamente de pessoas envolvidas na indústria têxtil. Workers Rights Consortium é uma organização independente de monitoramento de direitos trabalhistas.
} 
e colocou em marcha o National Tripartite Plan of Action ${ }^{33}$ e o Better Work joint management como parte do International Labor Organization -International Finance Corporation (ILO-IFC) ${ }^{34}$ (OIT, 2013a). Todos os esforços foram bem-sucedidos e desembocaram em ações concretas. A organização também lançou uma carta pública aos representantes do governo bengali em 1o. de maio daquele ano (OIT, 2013b).

Os Estados nacionais e a União Europeia, por sua vez, responderam com pressão, ameaça e, posteriormente, sanções comerciais ${ }^{35}$. No Estado bengali forjou-se uma crise das elites que levou a uma nova "estrutura de oportunidade política" ${ }^{\prime \prime 6}$ (Tarrow, 1989), e a uma efetiva mudança da estrutura de poder nacional. O Congresso era formado pela maioria ampla da Liga Bangladesh Awami, que possuía fortes relações de clientelismo, nepotismo, cronismo e rent-seeking (Khan; Wichterich, 2015) com a Bangladesh Garment Manufacturers and Exporters Association (BGMEA), uma relação que ficou profundamente abalada com a tragédia. Os sindicatos nacionais e internacionais, por sua vez, estabeleceram novas condições trabalhistas, nacionalmente, e mecanismos de enforcement, internacionalmente, a partir de ações de outros atores políticos envolvidos na tragédia, como a OIT, organizações de promoção de direitos trabalhistas e movimentos sociais. Deve-se apontar que, enquanto as mulheres eram relutantes em associarem-se aos sindicatos (devido à sua estrutura hierárquica masculinizada em uma indústria nacional em que $80 \%$ da força

\footnotetext{
33 Acordo nacional tripartite entre o Ministério do Trabalho bengali, trabalhadores e empregadores, com a assistência da OIT.

34 Programa da OIT para melhorar condições de trabalho em cadeias produtivas e tornar as empresas mais competitivas.

35 A União Europeia adotou uma resolução para pressionar a adoção das Convenções 187 e 155 por Bangladesh e ameaçou retirar o país do Sistema Geral de preferências (SGP) da OCDE (OIT, 2013c), eliminação efetivamente levada a cabo pelos Estados Unidos (Forbes, 2014).

${ }^{36}$ Estrutura de oportunidade política refere-se a "dimensões do ambiente político consistentes - mas não necessariamente formais, permanentes ou nacionais - que podem tanto encorajar quando desencorajar as pessoas a usarem ações coletivas" (Tarrow, 1998. p. 18, tradução nossa).
} 
laboral é de trabalhadoras mulheres), elas protestaram espontaneamente contra o não pagamento de horas extras no Bangladesh Independent Garment Workers Union (BIGUF) (Khan; Wichterich, 2015). Essa tendência se repetiu em São Paulo, por exemplo, nas manifestações da Marcha dos Imigrantes, ocasião em que as mulheres se sentiram à vontade para sair às ruas e protestar de maneira informal, sem a ameaça da polícia em deportá-las ${ }^{37}$.

As repercussões para o setor privado derivaram da exigência dos acordos mencionados, vinculantes e com a inclusão de cláusulas de reparação às vítimas. Ainda que tais acordos sejam temporários, o reconhecimento de corresponsabilidade empresarial, no caso Rana Plaza, aumentou o poder de sindicatos nacionais, seja pela vinculação de corresponsabilidade em acordos vinculantes nacionais, seja pela promoção e efetiva assinatura de acordos de governança transnacionais (como os Acordo Marco-Internacionais) (Khan; Wichterich, 2015; Accord, 2016).

Já as Federações Sindicais Internacionais, ou Global Union Federations, atualizaram acordos e compromissos através de Acordos-Marco e um novo programa de inspeções em fábricas. Em específico, o aumento do "diálogo social" entre a holding Inditex e a IndustriALL Global Union resultou na assinatura de um novo Acordo Marco Internacional, em julho de 2014, que prevê questões como: a responsabilidade de compliance dos fornecedores com os Standards do acordo; a extensão de direitos a todos(as) trabalhadores(as) da cadeia produtiva da empresa; o reconhecimento da IndustriALL como parceira legítima; a adesão às Convenções da OIT 29, 87, 98, 100 e 105, 111, 135, 138, 155, 159, 182; a Declaração Universal dos Direitos Humanos; à Convenção das Nações Unidas sobre os Direitos das Crianças; às Diretrizes da OCDE para Empresas Multinacionais; a provisão de informações à IndustriALL; a comunicação dialógi-

${ }^{37}$ Observação de campo. 
ca sobre violações do acordo na cadeia de produção da empresa; a comunicação do acordo por parte da Inditex a todos os seus fornecedores e por parte da IndustriALL a todos os seus afiliados; e a oferta de programas de treinamento conjuntos (Inditex; IndustriALL, 2014).

Internacionalmente, estabeleceram-se auditorias pontuais, por parte da IndustriALL, em plantas produtivas em alguns dos países onde a empresa opera, como projeto piloto: Portugal, Turquia, Camboja e Brasil (Intervención sindical - la experiencia de Inditex 2014: 11). No último, por exemplo, foi estabelecida parceria com a Confederação Nacional dos Trabalhadores na Indústria Têxtil, Couro e Calçado (CNTRV) da Central Única dos Trabalhadores (CUT), e com a Confederação Nacional dos Trabalhadores nas Indústrias do Setor Têxtil, Vestuário, Couro e Calçados (CONACCOVEST) da Força Sindical (FS).

Houve, ainda, atuação de outros movimentos sociais. O movimento estudantil United Students Against Sweatshops (USAS) promoveu tuitaços e incentivou o aumento da associação das universidades a vestuários certificados ${ }^{38}$ pela Workers Rights Consortium, sit-ins nos campi das universidades, ações em frente às lojas, panfletagens e a organização de Global Days of Action (USAS, 2016). A Marcha Mundial das Mulheres (MMM) ${ }^{39}$ realizou, em sua quarta ação, em 2015, movimentos de solidariedade com as trabalhadoras de Rana Plaza (MMM, 2015). As ações difusas de movimentos sociais resultaram tanto em medidas concretas (caso USAS,

\footnotetext{
38 Nos Estados Unidos as universidades têm tradição esportista. Os times de esporte das universidades são financiados por marcas como Nike e a pressão, pelo movimento estudantil, é de que as roupas utilizadas pelo corpo universitário (sejam os times que praticam esportes ou os itens vendidos nas lojas de roupa dos campi) tenham a certificação de trabalho digno na cadeia produtiva. É a essa função que se destina, em monitoramento independente, a Workers Rights Consortium.

39 A MMM é uma rede internacional que articula diversos coletivos, movimentos, associações e organizações de mulheres ao redor do mundo em torno de pautas comuns. A MMM é importante ao conscientizar difusamente a inter-relação entre trabalho e a precarização das vidas das mulheres.
} 
de assinatura de acordos com fornecedores socialmente responsáveis), quanto na conscientização (caso da MMM, de diálogo com bases sociais).

Do lado de ONGs, de grupos ligados às temáticas de Direitos Humanos, em particular as estratégias name and shame - de publicização e responsabilização social das grandes marcas, mais eficiente em indústrias voltadas ao consumidor final -, foram amplamente utilizadas. A Clean Clothes Campaign (2015) qualificou a tragédia do edifício Rana Plaza como "o pior acidente industrial da indústria de vestuário" (tradução nossa), promoveu a campanha "PayUp!" de compensação, tuitaços, atualizações periódicas sobre o posicionamento das empresas a respeito das compensações e manteve pressão cerrada sobre as empresas, dentre outras ações. A Workers Rights Consortium (2016) continuou a realizar relatórios periódicos e a promover roupas certificadas com selo de trabalho digno, bem como monitoramento independente sobre as grandes marcas. Tanto a Clean Clothes Campaign, quanto a Workers Rights Consortium, conquistaram cadeiras no acordo estabelecido de reparação às vítimas.

Todas as reações mencionadas acima levaram à assinatura dos seguintes acordos: Accordon Fire and Building Safety in Bangladesh (conhecido por "Accord"), National Tripartite Plan of Action (NTPA) e a Alliance for Bangladesh Workers' Safety (conhecido por "Alliance"), um novo arranjo institucional local que criou novas formas de cooperação e governança e produziu um novo marco regulatório para saúde e segurança no trabalho.

O The Accord é uma iniciativa multistakeholder e prevê responsabilidades compartilhadas entre agentes. A estrutura de governança do The Accord prevê: a criação de um Comitê Diretor (grupos mencionados no parágrafo anterior, juntamente com empresas ${ }^{40}$ ); uma "assembléia" com cadeiras compartilhadas entre sindicatos e empresas, um mecanismo de reclamação, outro de resolução de disputas e mediação, a rotina de ins-

${ }^{40}$ As empresas PVH, H\&M e a holding Inditex possuem cadeiras permanentes. 
peções de segurança; "direito de recusa ao trabalho" ${ }^{41}$; treinamentos de segurança; Comitês de Saúde e Segurança; base de dados pública e acessível; e sanções formais por non-compliance.

O NTPA foi um acordo temporário que durou de junho de 2013 a dezembro de 2014 e consistiu em 25 atividades planejadas nas áreas de legislação trabalhista e política (por exemplo, melhorias na legislação trabalhista bengali), administração (com aumento de fiscalização e aumento de segurança em locais de trabalhos) e atividades práticas (como compensação às vítimas e/ou suas famílias e reabilitação e realocação de trabalhadores/as desempregados/as).

Finalmente, a Alliance é considerada uma forma de contrato voluntário e flexível, comparado ao The Accord, por algumas marcas que não desejam ser acusadas de corresponsáveis pelo colapso do edifício Rana Plaza. A aliança tem a duração de 5 anos, envolve 26 das maiores marcas de roupas estadunidenses (como Gap e Wal Mart), conta com nove membros no Conselho Diretor do The Accord, com inspeções no nível da fábrica, e com um National Tripartite Committee Review Panel (Khan; Wichterich, 2015; The Accord, 2016).

A situação dos sweatshops em São Paulo corresponde a um contexto inteiramente diferente de Bangladesh. Observa-se uma maior regulação social e trabalhista no Brasil: os sindicatos de trabalhadores são instituições reconhecidas e, durante os governos de Lula da Silva, foram criados incentivos para coibir as piores formas de violação aos direitos trabalhistas, como o trabalho análogo à escravidão (a Lei 10.803, de 11 de dezembro de 2003) e a Lista Negra - que visa expor os empregadores que realizam violações trabalhistas. Dessa forma, no Brasil, percebe-se um maior poder do Estado, em comparação a Bangladesh, em fiscalizar

${ }^{41}$ Caso o/a trabalhador avalie que o local de trabalho não é seguro. 
e punir irregularidades no campo trabalhista, bem como um maior grau de independência entre mercado e estado e de poder dos sindicatos ${ }^{42}$.

No caso de ONGs e grupos de advocacy, outro ator político importante, além do sindicato, é a Pastoral dos Imigrantes, ligada à teologia da libertação da Igreja Católica, materializada na ONG Centro de Apoio aos Imigrantes (CAMI), por realizar o trabalho de base e conhecer de perto as centenas de sweatshops em São Paulo e região metropolitana, e por contribuir com o poder público no resgate de trabalhadores(as) em situação de vulnerabilidade. As táticas name and shame, utilizadas similarmente ao caso Bangladesh, mostraram-se recursos úteis a partir de ONGs como a Repórter Brasil. Importante destacar que as violações foram amplamente divulgadas pela grande imprensa brasileira. Assim como em Bangladesh, houve a presença da OIT, nesse caso de forma mais preventiva do que reativa ou de remediação.

Organizações não governamentais e organizações sindicais ${ }^{43}$ agiram conjuntamente com o poder público sob o guarda-chuva da OIT e amparados pela legislação nacional. Além disso, o projeto do Pacto Nacional pela Erradicação do Trabalho Escravo no Brasil, envolvendo a OIT, o Instituto Ethos, a Repórter Brasil e o Instituto Observatório Social da CUT atuaram como promotores da agenda do trabalho decente no país. Houve também, conforme mencionado, maior participação e enforcement estatais na promoção de trabalho decente: o Ministério do Trabalho e Emprego (MTE) lavrou 48 autos de infração contra a empresa; houve a participação de dois agentes da Polícia Federal (PF) e de integrantes do Núcleo de Enfrentamento ao Tráfico de Pessoas da Secretaria da Justiça

\footnotetext{
42 Embora o principal sindicato da categoria em São Paulo também mostre predomínio masculino e conte com o agravante de representar usualmente trabalhadores/as registrados/as.

43 Especificamente, em relação às ONGs, a Repórter Brasil e o Centro de Apoio ao Migrante. Em relação às organizações sindicais, o Sindicato das Costureiras de São Paulo e a Confederação Nacional dos Trabalhadores nas Indústrias do Setor Têxtil, Vestuário, Couro e Calçados (CONACCOVEST), ambos ligados à Força Sindical.
} 
e Defesa da Cidadania do Estado de São Paulo; e o envolvimento de auditores da Superintendência Regional do Trabalho e Emprego do Estado de São Paulo (SRTE/SP). Essas ações fizeram parte do Programa de Erradicação do Trabalho Escravo Urbano da SRTE/SP e do Pacto Contra a Precarização e Pelo Emprego e Trabalho Decentes em São Paulo - Cadeia Produtiva das Confecções (Repórter Brasil, 2011). Entre os principais resultados dessas ações, está a assinatura pela empresa Zara um Termo de Ajuste de Conduta (TAC), em 2011, após perceber o risco de uma ação civil pública que traria à companhia ainda mais penalidades.

As pressões da sociedade civil sobre o caso da tragédia do edifício Rana Plaza implicaram, também, em benefícios sobre o sistema de governança corporativa mundial da empresa ${ }^{44}$, o que afetou, inclusive, suas unidades produtivas brasileiras.

Bangladesh e São Paulo apresentam duas situações e contextos diferentes que envolvem a empresa. Em Bangladesh, tem-se uma tragédia global que impacta todas as partes interessadas, provoca uma crise de elites com a abertura de uma janela de oportunidades à participação da sociedade civil, que se consubstanciou em um novo arranjo institucional local multistakeholder ${ }^{45}$. No outro, eventos geradores (a sanção às violações) que fazem parte do enforcement, pelo Estado, das regulamentações trabalhistas. De todo modo, os casos estudados permitem afirmar que, onde o Estado possui os instrumentos de implementação da lei, e se o enforcement for robustecido pela sociedade civil, os resultados tendem a ser positivos e indicam que a Zara teve suas operações no Brasil "dis-

\footnotetext{
${ }^{44}$ São também elementos de governança da empresa o Código de Conduta, as Práticas Responsáveis, a Responsabilidade Social Empresarial; o Pacto Global e os Princípios Orientadores sobre Empresas e Direitos Humanos "Respect and Remedy" (ambos da ONU); os programas Trabalho Melhor (Better Work, Better Factories) e Ethical Trading Initiative (ambos da OIT); e o Sustainable Apparel Coalition and Better Cotton Initiative.

45 Iniciativas multistakeholder são instrumentos de governança que promovem bens públicos além do que fazem os governos nacionais e as Ols, e assim cumprem um papel na governança global que a autoridade pública não tem condições de prover, ver Hale e Held (2011).
} 
ciplinadas". Por essas características, a presença sindical analisada se fez importante, mas não decisiva, tanto na reparação de vítimas em Dhaka (Bangladesh), quanto na libertação de pessoas em condições análogas à de escravidão em São Paulo (Brasil) ou na elaboração de novos Acordos-Marco para a governança transnacional da empresa.

\section{Conclusão}

A organização da cadeia produtiva do vestuário, em escala global, apresenta características que impactam negativamente a organização dos trabalhadores do setor. A estratégia de uma das empresas líderes do fast fashion promove a terceirização e a precarização das relações de trabaIho, e é mimetizada por outras grandes empresas que procuram ganhar competitividade com a redução de custos na organização de suas cadeias de produção. Como a cadeia produtiva é transnacional, e o setor é intensivo em trabalho, são os(as) trabalhadores(as) do Sul Global os(as) que mais sofrem as consequências negativas da globalização do vestuário. Contudo, essa narrativa é apenas uma parte da história. As dificuldades dos(as) trabalhadores(as) em promoverem ação coletiva estão ligadas à forma de organização do trabalho, particularmente, a como a questão de gênero impacta as respostas sindicais às violações sociais e trabalhistas.

O gênero combina a dimensão fabril da produção de roupas com a experiência subjetiva de organização doméstica do lar por parte das muIheres trabalhadoras. Essas duas dimensões operam dentro das sweatshops fornecedoras da Zara em São Paulo. O objetivo de conquistar uma remuneração razoavelmente elevada no menor tempo possível acaba sendo o contraponto à ação coletiva. As mulheres trabalhadoras não conseguem promover um movimento de base e empoderamento (bottom-up) na direção de constituir um sujeito coletivo (um agente) - o sindicato ou outro ator coletivo que possa vocalizar interesses e encaminhar soluções. 
A questão de gênero coloca, assim, uma reflexão para o processo de transnacionalização da ação sindical. As mulheres trabalhadoras são parte integral dos processos de organização da produção e o caso da cadeia do vestuário é um exemplo claro. Sua emancipação de uma condição social subalterna deve problematizar as características da organização da cadeia de produção juntamente com a forma como o gênero impacta a organização familiar, e a dimensão subjetiva das relações familiares no espaço privado, doméstico. O presente artigo indica que essa dimensão traz implicações para a organização de trabalhadores(as) e ajuda a entender a dificuldade de promoção da ação coletiva sindical. As coalizões de diferentes stakeholders que falam em nome de trabalhadores(as) e se organizam no espaço transnacional podem ajudar a vocalizar as violações e até melhorar as condições de trabalho e a remuneração dos elos mais frágeis da cadeia do vestuário. Mas seria melhor se os(as) próprios(as) trabalhadores(as) do vestuário pudessem construir de baixo para cima sua própria instituição de representação política. Esse esforço faria com que as grandes empresas repensassem suas estratégias competitivas e a organização da cadeia produtiva poderia ser articulada de forma a promover direitos e melhorar as condições de trabalho de milhões de trabalhadoras e trabalhadores do Sul Global.

João Paulo Cândia Veiga é Doutor em Ciência Política (USP) e Professor da Faculdade de Filosofia, Letras e Ciências Humanas da USP, no Departamento de Ciência Política e no Instituto de Relações Internacionais (IRI).

$\measuredangle$ jpcandiaveiga@gmail.com

Katiuscia Moreno Galhera é Doutoranda em Ciência Política na Universidade Estadual de Campinas (UNICAMP), com período sanduíche na Universidade Estadual da Pensilvânia (PSU).

$\searrow$ katiuscia.mg1@gmail.com 


\section{Referências}

1. ACCORD ON FIRE AND BUILDING SAFETY IN BANGLADESH. Governance. Disponível em: http://bangladeshaccord.org/governance/. Acesso em 30 nov2016.

2. ANNER, M. The paradox of labour transnationalism: Trade union campaigns for labour standards in international institutions. In: PHELAN, C. The Future of Organized Labour: Global Perspectives. Bern: Peter Lang. p. 63-90, 2006.

3. ANNER, M. Solidarity Transformed: Labor Responses to Globalization and Crisis in Latin America. Ithaca: Cornell University Press, 2011.

4. ANNER, M. et al. Determinantes industriais da solidariedade transnacional: política intersindical global em três setores. Estudos avançados, v. 28, n. 81, 2014, pp.: 229-250.

5. ANNER, M.; EVANS, P. Building bridges across a double divide: alliances between US and Latin American labour and NGOs. Development in Practice, v. 14, n.1-2, 2004, pp.: 34-47.

6. BARBIERI, J. C.; CAJAZEIRA, J. E. R. Responsabilidade social empresarial e empresa sustentável: da teoria à prática. Editora Saraiva, 2013.

7. BOHME, S. R. Toxic Injustice: a transnational history of exposure and struggle. Orlando, CA (EUA): University of California Press, 2014.

8. BRAH, A. Diferença, diversidade, diferenciação. Cadernos Pagu. Campinas, n.26, pp.329-365, 2006.

9. BRONFENBRENNER, K. (Ed.) Global Unions: Challenging transnational capital through cross-border campaigns. Ithaca, MA, EUA: Cornell University Press, 2007.

10. BÜTHE, T.; MATTLI, W. The New Global Rulers: The Privatization of Regulation in the World Economy. Princeton, New Jersey: Princeton University Press, 2011.

11. BUTLER, J. Gender Trouble: Feminism and the subversion of identity. Nova York/Londres: Routledge, 2011.

12. CLEAN CLOTHES CAMPAIGN (2015). PayUp! Disponível em: https://cleanclothes.org/safety/ranaplaza/pay-up-old. Acesso em 23 dez 2016.

13. COLLINS, J. L. Threads: Gender, Labor and Power in the Global Apparel Industry. Chicago: University of Chicago Press, 2003.

14. CRENSHAW, K. Mapping the margins: Intersectionality, identity politics, and violence against women of color. Stanford Law Review, 1241-1299, 1991.

15. CROUCHER, R.; COTTON, E. Global Unions, Global Business: Global Union Federations and International Business. Londres: Middlesex University Press, 2009. 
16. DICKEN, P. Global Shift: Mapping the Changing Contours of the World Economy. Nova York: Guilford Press, 2007.

17. ENLOE, C. Bananas, Beaches and Bases: Making Feminist Sense of International Politics. 2 ed. Berkeley/Los Angeles, California: University of California Press, 2014.

18. FORBES. A Guide to the Rana Plaza Tragedy, and its Implications, in Bangladesh, 2014. Disponível em: http://www.forbes.com/sites/ alyssaayres/2014/04/24/a-guide-to-the-rana-plaza-tragedy-and-its-implicationsin-bangladesh/\#3ba56118211d. Acesso em 23 dez 2016.

19. GEREFFI, G. The Organization of Buyer-Driven Global Commodity Chains: How U.S. Retailers Shape Overseas Production Networks. In: GEREFFI, G.; KORZENIEWICZ, M. Commodity Chains and Global Capitalism. Westport: Praeger Publishers, 1994.

20. GRAY, C. Metalúrgicos Sem Fronteiras: Building a Global Union at Gerdau. (Dissertação de Mestrado). Ithaca: Cornell University, 2009.

21. GRAY, C. Riding Bicycles When We Need Cars: the Development of Transnational Union Networks in Brazil. (Tese de Doutorado). Ithaca: Cornell University, 2015.

22. GUIMARÃES, N. A. A igualdade substantiva e os novos desafios nas relações de gênero no trabalho. Estudos Feministas, v. 24, n. 02, p. 639-643, mai./ ago.2016.

23. HALE, T.; HELD, D. (Eds.) Handbook of Transnational Governance: Institutions and Innovations. Cambridge (Reino Unido): Polity Press, 2011.

24. HIRATA, H. Novas configurações da divisão sexual do trabalho. Revista Tecnologia e Sociedade, v. 6, n. 11, 2010, pp.: 1-7.

25. HIRATA, H.; KERGOAT, D. Novas configurações da divisão sexual do trabalho. Cadernos de Pesquisa, v. 37, n.137, pp. 595-609, set. 2007.

26. HO, L. et al. (Dis)assembling Rights of Women Workers along the Global Assembly Line: Human Rights and the Garment Industry. In: Berkeley Law Scholarship Repository, 1996. Disponível em:www.scholarship.law.berkeley.edu. Acesso em: 10 mar 2017.

27. HUMAN RIGHTS WATCH. Bangladesh: Rana Plaza Victims Urgently Need Assistance, 2014. Disponível em: https://www.hrw.org/news/2014/04/23/bangladesh-rana-plaza-victims-urgently-need-assistance. Acesso em: 23 dez 2016.

28. INDITEX. Annual Report, 2015. Disponível em: https://www.inditex.com/ documents/10279/208409/Inditex_+Annual_Report_2015_web.pdf/d3501c558e8f-4936-b8d8-0fc47a543c93. Ačesso em: 21 nov 2016. 
29. INDITEX; INDUSTRIALL GLOBAL UNION. Global Framework Agreement between Industria de DiseñoTextil, S.A. (Inditex, S.A.) and IndustriALL Global Union on the Implementation of International Labour Standards throughout the supply chain of Inditex. Disponível em: http://www.ibgc.org.br/index.php/governanca/governanca-corporativa. Acesso em: 21 nov 2016.

30. INDUSTRIALL. IndustriALL demands real action after fire in Bangladesh, 2013. Disponível em: http://www.industriall-union.org/industriall-demands-realaction-after-fire-in-bangladesh. Acessado em 15 de dezembro de 2016.

31. INSTITUTO OBSERVATÓRIO SOCIAL. "Que Moda é Essa?", artigo do jornalista Marques Casara, Observatório Social em Revista n. 10, maio, 2006.

32. INTERVENCIÓN SINDICAL. La experiencia de Inditex (comunicação interna), 2014.

33. ISTO É DINHEIRO. A C\&A Vira do Avesso: entrevista com o presidente Paulo Correa, 2016. Disponível em: http://www.istoedinheiro.com.br/noticias/negocios/20161118/vira-avesso/433670. Acesso em: 22 dez 2016.

34. JURAVICH, T.; BRONFENBRENNER, K. Ravenswood. Nova York: Cornell University Press, 1999.

35. KHAN, M. R. I.; WICHTERICH, C. Safety and labour conditions: the accord and the national tripartite plan of action for the garment industry of Bangladesh. OIT, 2015.

36. LAM, L. Designer Duty Extending Liability to Manufacturers for Violations of Labor Standards in Garment Industry Sweatshops, University of Pennsylvania Law Review, v. 141, n. 2, p. 623-667, 1992.

37. LYNCH, C. Juki Girls, Good Girls: Gender and Cultural Politics in Sri Lanka's Global Garment Industry. Ithaca, EUA: Cornell University Press, 2007.

38. LOUIE, M. C. Y. Sweatshop Warriors: Immigrant Women Workers Take on the Global Factory. Cambridge, Massachusetts: South End Press, EUA, 2001.

39. MARCHA MUNDIAL DAS MULHERES. Trabalho escravo contemporâneo: qual sua relação com as mulheres? 2015. Disponível em: https://marchamulheres. wordpress.com/tag/rana-plaza/. Acesso em 23 dez 2016.

40. MATTHEWMAN, S. Disasters, Risks and Revelation: Making sense of our times. New York: Palgrave Macmillan, 2015.

41. MCCLINTOCK, A. Imperial leather: Race, gender and sexuality in the colonial contest. Londres: Routledge, 1995.

42. OIT. Conclusions of the ILO's high level mission to Bangladesh.2013a. Disponível em: http://www.ilo.org/global/about-the-ilo/newsroom/statementsand-speeches/WCMS_212463/lang--en/index.htm. Acesso em: 23 dez 2016. 
43. OIT. Statement by ILO Deputy Director General in Bangladesh on May Day 2013. 2013b. Disponível em: http://www.ilo.org/global/about-the-ilo/newsroom/statements-and-speeches/WCMS_212189/lang--en/index.htm. Acesso em: 23 dez 2016.

44. OIT. ILO mission to Bangladesh results in action plan for reforming garment industry. 2013c. Disponível em: http://www.ilo.org/brussels/WCMS_212829/ lang--en/index.htm. Acesso em: 23 dez 2016.

45. NORTH, D. Institutions, Institutional Change and Economic Performance. Cambridge (Reino Unido): Cambridge University Press, 1990.

46. OLSON, M. The Logic of Collective Action: Public Goods and the Theory of Groups. Cambridge: Harvard University Press, 1965.

47. REPÓRTER BRASIL (2011). Roupas da Zara são fabricadas com mão de obra escrava. Disponível em: http://reporterbrasil.org.br/2011/08/roupas-dazara-sao-fabricadas-com-mao-de-obra-escrava/. Acesso em: 30 nov 2016.

48. ROMBALDI, M. Internacionalização do sindicalismo no Brasil: um estudo sobre os setores metalúrgico e de telecomunicações. 2012. Tese (Doutorado em Sociologia). Faculdade de Filosofia, Letras e Ciências Humanas, Universidade de São Paulo, São Paulo.

49. SCOTT, J. Gender: A Useful Category of Historical Analysis. The American Historical Review, v. 91, n.5, dez 1986, pp. 1053-1075.

50. SILVER, B. Forces of labor: worker's movement and globalization since 1870. Nova York: Cambridge University Press, 2008.

51. SANTOS, B. de S. Trabalhar o mundo: os caminhos do novo internacionalismo operário. v. 5. Rio de Janeiro: Editora Record, 2005.

52. TARROW, S. Democracy and Disorder: Protest and Politics in Italy, 19651974. Nova York: Oxford University Press, 1989.

53. THE ECONOMIST. Rags in the ruins. 2003. Disponível em: http://www. economist.com/news/asia/21577124-tragedy-shows-need-radical-improvementbuilding-standards-rags-ruins. Acesso em: 23 dez 2012.

54. TILLY, C. The Contentious French: Four Centuries of Popular Struggle. Cambridge, MA: Harvard University Press, 1986.

55. UNITED STUDENTS AGAINST SWEATSHOPS. Garment Worker Solidarity. 2016. Disponível em: http://usas.org/campaigns/garment-worker-solidarity/. Acesso em: 15 dez 2016. 
56. VEIGA, J. P.; GALHERA, K. Monitoring Precarious and Forced Labor in Brazil: Sweatshops in São Paulo from a Gender Perspective. In: WOUTERS, J. $\square$ RAYP, G. $\square$ BEKE, L. $\square$ MARX, A. (Org.). Protecting Labor Rights in a Multipolar Supply Chain and Mobile Global Economy. 1a. ed. Netherlands: Kluwer Law International, 2015.

57. VEIGA, J. P.; GALHERA, K. Entre o lar e a 'fábrica': trabalhadoras bolivianas da costura na cidade de São Paulo. In: FIGUEIRA, R. R.; PRADO, A. A.; GALVÃO, E. M. (Org.). Discussões contemporâneas sobre trabalho escravo: teoria e pesquisa. 1ed. Rio de Janeiro: Mauad, 2016, pp. 119-145.

58. WEBSTER, E.; LAMBERT, R.; BEZUIDENHOUT, A. Grounding globalization: Labour in the age of insecurity. Nova York: John Wiley \& Sons, 2008.

59. WORKERS RIGHTS CONSORTIUM. Mission. 2016. Disponível em: http:// www.workersrights.org/about/. Acesso em: 4 dez 2016.

Recebido em: 05.01.2017

Aceite em: 09.02.2017 